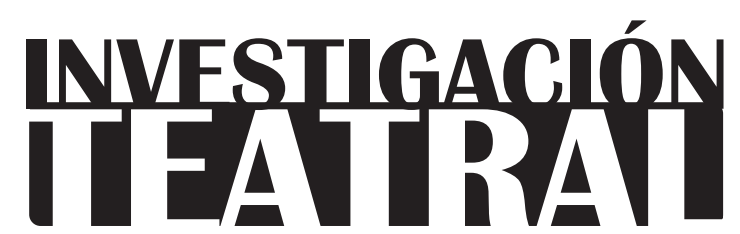

Revista de artes escénicas y performatividad

Vol. 10, Núm. 16

octubre 2019-marzo 2020

Segunda época

ISSN impreso: 1665-8728

ISSN electrónico: 2594-0953

Universidad Veracruzana

Reseña del libro:

\title{
Los patriotas en escena (1862-1869), de Miguel Ángel Vásquez Meléndez
}

\author{
Guillermina Fuentes Ibarra*
}

\footnotetext{
* Centro Nacional de Investigación, Documentación e Información Teatral "Rodolfo Usigli", Instituto Nacional de Bellas Artes y Literatura, México e-mail: gfuentesibarra.citru@inba.edu.mx
}

Recibido: 28 de marzo de 2019

Aceptado: 05 de julio de 2019

Doi: $10.25009 /$ it.v10i16.2613 


\section{Los patriotas en escena (1862-1869), de Miguel Ángel Vásquez Meléndez}

Vásquez Meléndez, Miguel Ángel. Los patriotas en escena (1862-1869). Ciudad de México: El Colegio de México, Centro de Estudios Históricos, 2018, 160 pp.

$\mathrm{E}$ 1 fenómeno teatral es un constructo ideológico que puede contribuir al fervor patrio en momentos específicos de la historia de un país. Como se plantea en el libro Los patriotas en escena (1862-1869), a partir del texto dramático y su puesta en escena se explica cómo los dramaturgos mexicanos de la segunda mitad del siglo XIX influyeron en la subjetividad de los espectadores de aquella época. Es así como las puestas en escena se convirtieron en asambleas populares enmarcadas en el devenir histórico-social y político de los años que marcaron la segunda intervención francesa (1862-1867).

El autor de este libro, Miguel Ángel Vásquez Meléndez, es investigador del Centro Nacional de Investigación, Documentación e Información Teatral Rodolfo Usigli (CITRU) e integrante del Seminario de Historia de la Vida Cotidiana, coordinado por la doctora Pilar Gonzalbo, en el Colegio de México, desde 2004. En 2005, el seminario presentó la colección de libros acerca de la Historia de la vida cotidiana en México, en coedición con el Fondo de Cultura Económica, en donde también hay un artículo de Vásquez Meléndez; esto quiere decir que Los patriotas en escena (1862-1869) es un trabajo que se inscribe en la concepción, metodología y línea de dicho ejercicio académico.

Como producto del Seminario de Historia de la Vida Cotidiana, en 2018 surgieron los textos que conforman la colección "La aventura de la vida cotidiana", editada por el Colegio de México. El propósito de estos estudios es llegar al lector interesado en la historia de las personas comunes, es decir, aquellos sujetos sin rasgos distintivos que no son los "hombres grandes" o "heroicos", sino personas desconocidas que desempeñaron un papel en escenarios públicos pequeños o locales, como diría Eric Hobsbwan en su libro Gente poco corriente. Resistencia, rebelión y jazz. Una parte del contenido del texto expone el 
proceso de creación del relato histórico y esto es de suma importancia, sobre todo para aquellos interesados en la narración histórica y en los procesos de creación que los autores comparten al contar cómo llegaron a elaborar los textos de esta colección.

En el caso de Los patriotas en escena advertimos, en una primera parte, que el doctor Vásquez Meléndez, por haber trabajado en el Archivo General de la Nación (AGN) y en el CITRU -en este último desde 1989 a la fecha-, se ha involucrado en el estudio de la historia del teatro, particularmente del decimonónico. Nos revela que "la revisión sumaria de fuentes de primera mano se convirtió en un hábito" (13); por ello, la indagación de sus investigaciones se centra en documentos del AGN y del Archivo Histórico de la Ciudad de México, sin dejar de lado carteleras, crónicas y reseñas, material hemerográfico concentrado en diferentes bibliotecas de la ciudad.

Para la elaboración del texto aquí reseñado, Vásquez Meléndez cuenta cómo articula el discurso histórico, de dónde toma la información, cómo la analiza y qué trascendencia tienen anécdotas o costumbres al reconocerse como hechos sociales; de ahí la importancia que da a la consulta de documentos de archivo. Es decir, muestra a los lectores nóveles el proceso de elaboración del tema que él desarrolla, cuyo propósito también es del seminario.

La segunda y tercera parte del contenido del libro son, propiamente, el relato y análisis históricos. Vásquez Meléndez, como muchas veces lo ha dicho en persona, periodiza y pone en primer plano los acontecimientos teatrales. Por eso no es de extrañar que el relato inicie en 1842, al realizarse la ceremonia de colocación de la primera piedra de un teatro en la Ciudad de México, pues, como es sabido, estudiosos y literatos del siglo XIX coincidían en la pertinencia de fomentar el gusto por las representaciones teatrales para mostrar el progreso del país en la época independiente, así como para revelar el talento peculiar de sus actores y dramaturgos (30-31).

Como bien dice Vásquez Meléndez, la dramaturgia y la escena conmemorativas de un hecho histórico, o dedicadas a un militar, gobernante o caudillo, son una vía para la construcción de la memoria histórica (33) y "fuente del estudio de la vida cotidiana, del imaginario colectivo, o de la difusión de principios políticos y de las noticias acerca de un conflicto bélico" (73).

Así, en Los patriotas en escena, Vásquez Meléndez da cuenta de cómo, al asumir los liberales la presidencia, el gran teatro de Santa Ana fue afectado por el descontento popular al destruir la fachada y monumentos alusivos a su Alteza Serenísima. Por esas mismas fechas, en las temporadas regulares, Vicente Riva Palacio y Juan A. Mateos lograron el estreno de sus piezas recién escritas, acontecimiento extraordinario ante la preferencia por los autores extranjeros que proporcionaban ganancias seguras a los empresarios (41).

Llama la atención el seguimiento que realiza durante el periodo de la intervención francesa y cómo los dramaturgos, por medio de sus piezas, llaman a la defensa de la pa- 
tria (44). El autor brinda un ejemplo de la función que cumplieron el drama y la escena en ese periodo:

La posibilidad de difundir los triunfos militares con las obras alusivas y el interés de aumentar las ganancias económicas en los inmuebles teatrales propiciaban la conjunción de líderes políticos y empresarios para producir este tipo de funciones, organizadas inmediatamente después de los acontecimientos aludidos. Para ello contaban con la capacidad de los escritores y compositores para crear piezas dramáticas de los acontecimientos recientes, improvisaciones corregidas y aumentadas en funciones posteriores o para su publicación; al igual que piezas musicales estructuradas con tonadas populares, versos improvisados, mezcla del ingenio de los autores y referencias a eventos de actualidad, conocidos por los oyentes y por tanto de fácil comprensión, y además con la posibilidad de mejorarlos antes de su edición en los periódicos políticos, de caricaturas o revistas literarias. Las funciones teatrales operaban de esta manera como una especie de periódico o representación audiovisual amena y espectacular, de acontecimientos de actualidad, dirigida a la población en su mayoría analfabeta, pero atenta a la situación política reflejada en los escenarios (49-50).

Con esa postura, los autores dramáticos liberales contribuyeron a la construcción, en el imaginario colectivo, de la noción de una identidad, de una mexicanidad, de una nación y de sus héroes, como Ignacio Zaragoza.

En el tercer capítulo, con una perspectiva histórica, Vásquez Meléndez toma tres piezas destinadas a la escena y las agrupa en un constructo dramático que denomina La República en tres actos: El embrollo mexicano, ¿cuál será el fin de la comedia? (1862), Mi amor, bandera y laurel; o sea, la enseñanza nacional (1869) y Loa patriótica (1869). La primera alude a la incertidumbre de la suerte de los republicanos ante la invasión francesa; la segunda pretende fortalecer el gobierno de la República Restaurada, y la última, que formó parte de los protocolos festivos de ese año, construye la imagen de un futuro esperanzador (73-74).

El autor muestra cómo, por medio de estos ejemplos, los autores dramáticos fueron construyendo una ideología nacionalista. Al ponderar las virtudes sobre los vicios en el personaje que se fue perfilando como pueblo mexicano, anota que:

[...] se trazó la imagen romántica de los sectores menos privilegiados, modelos de virtudes, honestos, trabajadores, humildes, inteligentes y, en síntesis, patriotas defensores de la independencia y la soberanía, antagonista de los extranjeros, plagados de vicios, impostores representantes de la tiranía, la ignorancia, el oscurantismo y, en extremo, de algunos pecados capitales, base de la dominación externa que pretende 
modificar las sanas costumbres ancestrales de los oriundos del país. El modesto y sensato guarda aduanal es la imagen de este sector social que confronta al extravagante y desquiciado archiduque, que debe ser repelido por los lectores de la comedia, una reacción buscada por los autores de las creaciones literarias de tendencia liberal, luego de despertar el sentimiento de animadversión hacia los foráneos (82-83).

Para constatar lo anterior, el autor transcribe algunos pasajes de las piezas dramáticas, en donde también enfatiza el modo en que la población de estos sectores sociales vivía su cotidianidad.

La última parte refiere a la relación teatro e historia, en donde el autor justifica cómo encuentra "propicio para el estudio de esta interrelación" el periodo 1862-1869, pues percibe un fuerte lazo entre el acontecimiento histórico y el surgimiento de dramas nacionalistas, próximos al ideario liberal. Además, apoyándose en investigaciones del historiador y estudioso teatral del siglo xix Enrique de Olavarría y Ferrari, sugiere que este tipo de piezas impactó la cultura política de un sector social durante el periodo de la invasión y aún después (112-113). También nos muestra que los empresarios teatrales "mantuvieron una posición apolítica o, si se prefiere, adaptable a los distintos grupos de poder... [pero] al mismo tiempo encontraron en las funciones conmemorativas, de homenaje y de recepción de los distintos gobernantes, opciones redituables, atractivas para el público" (135-136).

Como se dijo anteriormente, Los patriotas en escena es un texto que, a partir del fenómeno teatral, se construye, explica y relaciona con el devenir histórico-social y político de los años que marcaron la segunda intervención francesa. No resta más que decir que es un libro en formato de bolsillo, escrito de manera amena, de fácil lectura, pero con una consistencia vigorosa en su contenido, con la finalidad de llegar a un público amplio, objetivo que, a mi parecer, se cumple. 